from the departure of those directly responsible for the blunders and mismanagement. Sir Duncan Nichol, the chief executive of the management executive, told the Committee of Public Accounts that a series of measures had been put in train. These include training for authority members to "explain to them the ethos, the culture of the sector that they are joining," sending out guidelines on "standards of business conduct for NHS staff," and, most recently, issuing for consultation a code of conduct for members of NHS boards (see $\mathrm{p} \mathrm{225)}$. The poor performance of Wessex and the West Midlands may also have contributed to the decision to abolish, in effect, regional health authorities in their present form.

Moreover, the experience of those cross examined by the Committee of Public Accounts should in itself send out a strong message to the NHS as a whole. It would be difficult to imagine a more gruelling experience. The message would be stronger still but for the fact that it was not those directly responsible for the waste of $£ 30$ million who were examined (most of whom seem to have retired with comfortable gratuities or pensions) but their successors who were left to carry out the post mortem examination.

More fundamental changes may, however, be needed. The dilemma of accountability in the $\mathrm{NHS}^{6}$ is that, although the secretary of state is answerable to parliament for everything that happens, the centre has only a limited capacity to control events at the periphery: if it tried to keep a tight grip on everything that happened it would soon bring the NHS to a standstill. This suggests that the management executivewhich currently seems to be suffering from an acute attack of hyperactivity - should be much more selective in what it tries to control.

More importantly the scandals in Wessex and the West Midlands raise a crucial question about the secretary of state's selection of people to chair authorities and to become members of authorities. They are crucial links in the chain of accountability: in the words of Aneurin Bevan, they are the agents or creatures of the department. ${ }^{7}$ The scandals therefore raise serious questions about the judgment of, and the criteria used by, Mrs Bottomley's predecessors when they appointed those involved. Perhaps, therefore, the House of Commons should now call Mrs Bottomley to account for the principles of selection used in making such appointments: to dispel the suspicion, if she can, that pliability and political correctnessrather than independence of mind and a willingness to confront both managers and ministers-are the main qualifications required.

RUDOLF KLEIN

Centre for the Analysis of Social Policy,

University of Bath,

Bath BA2 7AY

\footnotetext{
1 Committee of Public Accounts. Wessex Regional Health Authority regional information systems plan Sixty-third report session 1992-1993. London: HMSO, 1993. (HC 658.)

2 Warden J. Managers put technology before patients, say MPs. BMf 1994;308:11-2

3 Committee of Public Accounts. West Midlands Regional Health Authority: regionally managed services

organisation. Fifty-seventh report session 1992-1993. London: HMSO, 1993. (HC 485.)

4 Warden J. NHS waste of funds was shambles, says committee. BMF 1993;307:1443.

5 NHS Management Executive. Standards of business conduct for NHS staff. Leeds: NHS Management Executive, 1993. (HSG(93)5.)

Klein R. The politics of the NHS. Lndon: Longman, 1989.

7 Day P, Klein R. Accountabilities. London: Tavistock, 1987.
}

\title{
Thrombolysis in myocardial infarction
}

\author{
The earlier the better, but how late is too late?
}

The development of myocardial necrosis after occlusion of the coronary artery is time dependent. Animal data suggest that irreversible damage occurs within three to four hours, ${ }^{1}$ but the pattern in clinical myocardial infarction is more complex as coronary occlusion may be a stuttering event and myocardial viability may be preserved by collateral flow. ${ }^{2}$

The relation between delay to thrombolytic treatment and survival benefit was first investigated adequately by the Gruppo Italiano per lo Studio della Streptochinasi nell'Infarto Miocardico and in the second international study of infarct survival. ${ }^{34}$ The Italian investigators found that the risk of death fell by a quarter in patients treated within three hours of the onset of symptoms and by a fifth in those treated three to six hours after the onset of symptoms. An analysis of patients treated within one hour suggested that the risk was halved. Similar trends were evident in the second international study of infarct survival. Neither trial, however, was designed specifically to evaluate the relation between the time of treatment and survival, and the trends were not significant.

The delivery of thrombolytic treatment in hospital is subject to inherent delays-the delay before the patient calls for help, the time taken by the general practitioner or ambulance to respond, the journey time to hospital, and the "door to needle" time in hospital. The current median interval between onset of pain and the start of treatment in British hospitals is three to four and a half hours. ${ }^{56}$ Although "fast track" policies can shorten the in hospital delay, another approach is to attempt prehospital thrombolysis.

Three recently completed randomised controlled trials have compared prehospital with in hospital thrombolysis. ${ }^{7-9}$ Patients with suspected myocardial infarction in the largest trial (the European myocardial infarction project) were randomised to receive either anistreplase by intravenous injection before admission with placebo by injection in hospital or vice versa. ${ }^{7}$ The median difference in time between the prehospital and in hospital treatment was 55 minutes; the in hospital door to needle time was 15 minutes. The total mortality at 30 days was not significantly lower in the group treated with thrombolysis before admission, although deaths due to cardiac causes fell significantly by $16 \%$. Meta-analysis of available trials suggests that prehospital thrombolysis achieves an overall reduction of $17 \%$ in the risk of death. ${ }^{7}$

A clear survival advantage for prehospital treatment was reported in the European myocardial infarction project when the interval between prehospital and in hospital treatment exceeded 90 minutes. The $42 \%$ reduction in mortality seen under these conditions is comparable with the figure of $49 \%$ reported in a trial of prehospital thrombolysis by general practitioners. ${ }^{8}$ In this study the median interval between prehospital and in hospital treatment was 139 minutes. Given that the median door to needle time in many hospitals is $\mathbf{5 5}$ to 89 minutes, ${ }^{56}$ these data emphasise the importance of streamlining procedures in accident and emergency departments and justify the use of thrombolytic treatment by general practitioners equipped with an electrocardiograph, particularly in rural areas where journey times to hospital exceed 30 minutes.

The upper time limit at which thrombolytic treatment is 
worth while was initially considered to be six hours. Data from the Gruppo Italiano per lo Studio della Streptochinasi nell'Infarto Miocardico failed to show significant benefit beyond this time and suggested an adverse trend at nine to 12 hours. These observations were not supported in the second international study of infarct survival in which the reduction in risk achieved by streptokinase and aspirin therapy was $32 \%$ at five to 12 hours and $39 \%$ at 13 to 24 hours. These apparently conflicting observations were based on relatively small numbers of randomised patients, and the confidence intervals were wide. Two further randomised trials of delayed thrombolysis have been published recently. The effect of alteplase $100 \mathrm{mg}$ was compared with that of placebo in 5700 patients presenting six to 24 hours after the onset of symptoms in the late assessment of thrombolytic efficacy study,,$^{10}$ while in the trial by the Estudio Multicentrico Estreptoquinasa Republicas de America del Sur Collaborative Group streptokinase $1.5 \mathrm{mU}$ was compared with placebo in 4500 patients, of whom $85 \%$ were randomised between seven and 24 hours after the onset of symptoms. ${ }^{11}$ Neither trial showed a significant fall in overall mortality at 35 days. Prespecified survival analysis of treatment six to 12 hours after the onset of symptoms showed a significant fall in mortality from $12 \%$ to

1 Jennings RB, Sommers HM, Herdson PB, Kaltenbach JP. Ischemic injury of myocardium. Ann NY Acad Sci 1969;156:61-78.

2 De Wood MA, Stifter WF, Simpson CS, Spores J, Eugster GS, Judge TP, et al. Coronary arteriographic findings soon after non-Q wave myocardial infarction. $N$ Engl f Med 1986;315: 417-22.

3 Gruppo Italiano per lo Studio della Streptochinasi nell'Infarto Miocardico (GISSI). Effectiveness of intravenous thrombolytic treatment in acute myocardial infarction. Lancet 1986;i:397-402.

ISIS-2 (Second International Study of Infarct Survival) Collaborative Group. Randomised trial of SIS-2 (Second International Study of Infarct Survival) Collaborative Group. Randomised trial of intravenous streptokinase, oral aspirin, both, or neither among 17187 cases of suspected acute

Wallbridge DR, Tweddel AC, Martin W, Cobbe SM. The potential impact of patient self-referral on mortality in acute myocardial infarction. Qf Med 1992;85:901-9.

6 Birkhead JS. Time delays in provision of thrombolytic therapy in six district hospitals. BMf 1992;305:445-8.
$8.9 \%$ in the late assessment of thrombolytic efficacy study ${ }^{10}$ and a non-significant fall from $14 \cdot 7 \%$ to $12 \cdot 7 \%$ in the South American study. ${ }^{11}$ Neither trial found that treatment between 13 and 24 hours after the onset of symptoms produced a significant fall in mortality. Taken together, these and other studies suggest that thrombolytic treatment between seven and 12 hours achieves a significant reduction in mortality, with 16 fewer patients dying per 1000 treated, while treatment between 13 and 24 hours reduces the number of deaths by five per 1000 patients treated. ${ }^{12}$

The data from all available trials consistently suggest that maximum benefit is achieved by early thrombolysis. Every effort should be made to streamline prehospital and in hospital procedures and to audit performance. On the available evidence, all patients without contraindications to thrombolysis who present with ST segment elevation or bundle branch block up to 12 hours after the onset of symptoms should be treated. The identification of subgroups who may benefit from treatment after 12 hours requires further study.

STUART M COBBE

Glasgow Royal Infirmary, Walton professor of medical cardiology Glasgow G31 2ER

7 European Myocardial Infarction Project Group. Prehospital thrombolytic therapy in patients with suspected acute myocardial infarction. $N$ Engl f Med 1993;329:383-9.

8 GREAT Group. Feasibility, safety, and efficacy of domiciliary thrombolysis by general practitioners: Grampian region early anistreplase trial. $B M \mathcal{F} 1992 ; 305: 548-53$.

Weaver DW, Cerqueira M, Hallstrom AP. The myocardial infarction triage and intervention trial of pre-hospital versus hospital initiated thrombolytic therapy. $\mathscr{F}$ (LA (in press).

0 LATE Study Group. Late assessment of thrombolytic efficacy (LATE) study with alteplase 6-24 hours after onset of acute myocardial infarction. Lancet 1993:342:759-66.

1 EMERAS (Estudio Multicentrico Estreptoquinas Republicas de America del Sur) Collaborative Grous (Bstomis Group. Randomised trial of late thrombolysis in patients with suspected acute myocardial

12 Fibrinolytic Therapy Trialists' (FTT) Collaborative Group. Indications for fibrinolytic therapy in suspected acute myocardial infarction: collaborative overview of early mortality and majo morbidity results from all randomised trials of more than 1000 patients. Lancet (in press).

\title{
What to do about halitosis
}

\author{
Regular use of toothbrush and dental floss
}

A degree of halitosis (oral malodour or foetor oris) is common in healthy people, particularly after sleep. It seems to originate from the mouth, resulting from the metabolic activity of bacteria present in oral plaque. Halitosis at other times is a distressing complaint from which few people probably escape completely and which is still incompletely understood. The true prevalence is not known, but one recent study suggested that nearly half of a group of young women (dental hygienists) believed that they sometimes had halitosis. ${ }^{1}$

Halitosis generally has as its basis bacterial putrefaction of food debris, cells, saliva, and blood. ${ }^{2}$ In particular, proteolysis of proteins to peptides, amino acids, and thence substrates with free thiol groups, such as cysteine and reduced glutathione, gives rise to volatile fluids and sulphides. ${ }^{3}$ Acetone, acetaldehyde, ethanol, propanol, and diacyl are also important causes of halitosis but, perhaps surprisingly, amines, indole, and skatole do not seem to be aetiologically important. ${ }^{4}$

People who refrain from cleaning their mouth soon develop halitosis, ${ }^{5}$ but any form of oral sepsis can produce appreciable malodour, the most common condition being inflammatory, plaque related gingival disease (gingivitis) or periodontal disease (periodontitis). The amounts of volatile sulphur compounds and the ratio of methylmercaptan to hydrogen sulphide are higher in the mouth air from patients with periodontal disease than in that from people with healthy mouths. ${ }^{67}$ The source of these compounds seems to be the gingival crevice, periodontal pockets, and the tongue coating. ${ }^{67}$ Sulphides identified from gingival crevicular sites include hydrogen sulphide, methylmercaptan, dimethyl sulphide, and dimethyl disulphide. ${ }^{8}$ Concentrations of these sulphides in mouth air seem to be particularly associated with oral spirochaetes and motile rods. ${ }^{9}$ Other oral sources of infection can cause malodour, as can sinusitis, foreign bodies in the nose, and respiratory infections.

Many foods and drinks can cause transient malodour, especially garlic, onions, and curries. Smoking and drugs, including occasionally alcohol, isosorbide dinitrate, and disulfiram, may also be implicated. Rare causes include diabetic ketoacidosis and severe renal or hepatic dysfunction. A recent possible link has been suggested between Helicobacter pylori and halitosis, ${ }^{10}$ but this is unsubstantiated. Halitosis may also be imaginary (delusional halitosis) ${ }^{11}$ or a hallucinatory feature in schizophrenia or temporal lobe epilepsy.

The management of halitosis requires establishing the presence of true halitosis and assessing its severity. People are usually good judges of the degree of malodour but, as 